University of Washington Tacoma

UW Tacoma Digital Commons

$9-27-2018$

\title{
Uniting Action Research and Citizen Science: Examining the Opportunities for Mutual Benefit Between Two Movements Through a Woodsmoke Photovoice Study
}

Robin A. Evans-Agnew

University of Washington Tacoma, robagnew@u.washington.edu

Chris Eberhardt

Follow this and additional works at: https://digitalcommons.tacoma.uw.edu/nursing_pub

Part of the Nursing Commons

\section{Recommended Citation}

Evans-Agnew, Robin A. and Eberhardt, Chris, "Uniting Action Research and Citizen Science: Examining the Opportunities for Mutual Benefit Between Two Movements Through a Woodsmoke Photovoice Study" (2018). Nursing \& Healthcare Leadership Publications. 161.

https://digitalcommons.tacoma.uw.edu/nursing_pub/161

This Article is brought to you for free and open access by the Nursing \& Healthcare Leadership at UW Tacoma Digital Commons. It has been accepted for inclusion in Nursing \& Healthcare Leadership Publications by an authorized administrator of UW Tacoma Digital Commons. 
Article Title:

Uniting action research and citizen science: Examining the opportunities for mutual benefit between two movements through a woodsmoke photovoice study.

\author{
Authors: \\ Robin A. Evans-Agnew, PhD, RN, (Corresponding) \\ Associate Professor \\ Nursing and Healthcare Leadership \\ University of Washington Tacoma \\ Box 358421 \\ 1900 Commerce Street \\ Tacoma \\ Washington 98402 \\ 2066051863 \\ FAX: 2536924424 \\ robagnew@uw.edu \\ Chris Eberhardt, $\mathrm{PhD}$ \\ 1007 N M ST APT 2 \\ Tacoma \\ Washington 98403 \\ 2534576618 \\ eberharc@alumni.newschool.edu
}

Abstract : As an emerging movement in participatory inquiry, citizen science presents an opportunity for advancing the disciplinary reach and usefulness of action research. In this article, we explore this opportunity by considering a case study involving youth-driven air sampling, photovoice, and environmental justice in the Pacific Northwest. When combined with photovoice as an action research method, citizen scientists can be empowered through collective learning to transform themselves from data collectors into builders of community knowledge and generators of policy change.

Key Words: Woodsmoke, Air pollution, Air Sampling, Critical Theory, Photovoice, Citizen Science, Adolescent, Youth Action Research, Levoglucosan, Environmental Justice, Pacific Northwest, Asthma 


\section{Disclosures:None}

Acknowledgements: We wish to acknowledge the contributions of the young men and women participants of this study. The following organizations contributed meeting space and facilities to this study: The Tacoma-Pierce County Health Department and the University of Washington Tacoma Center for Urban Waters. We thank Alex Gipe, Dr. Justin Miller-Schultze, Dr. Joel Baker, Kathy Ross, Dr. Jamilia Sherls, Dr. Mattie Brickle, and Melissa Workman who assisted with recruitment, data collection, and analysis. We thank Stacy Evans-Agnew who edited the final version of this manuscript.

Declaration of conflict of interest: The authors have no conflicts of interest or financial ties to disclose with respect to the research, authorship, and/or publication of this article.

Funding: We received financial support from University of Washington Royalty Research Fund 
Citizen science emerged in the 1990's as a movement for participatory research that sought to involve the public in the collection and analysis of data addressing issues of concern including action for policy change (Bonney, Cooper, \& Ballard, 2016; European Citizen Science Association, 2015; Irwin, 1995). These ideals resonate with the fundamental goals of action research (AR) (Bradbury, 2015b). Citizen science researchers however have yet to fully address the interests of the movement in engaging the participation of citizen scientists for policy action (Averett, 2017).

In contrast to citizen science, action research is a diverse movement for "the democratic and participatory orientation to knowledge creation [bringing] together action and reflection, theory and practice, in pursuit of practical solutions to pressing concerns. It is a pragmatic co-creation of knowing with, not on, people" (Bradbury, 2015b, p. 1). Action research is characterized by its orientation to social action and reflexivity and to a consciousness for the integration of subjective, intersubjective, and objective knowledge (Chandler \& Torbert, 2003). Both citizen science and action research movements share similar non-mainstream principles concerning participation and policy action. Yet citizen science is commonly viewed as keeping participants the role of data collectors (Averett, 2017) while action research stresses engagement of participants as stakeholders and offering them value (Bradbury, 2015b).

As feminist researchers from nursing and social science concerned with environmental justice and indoor air pollution, we became interested in the opportunities presented in the overlap between these two movements, especially opportunities for advancing the usefulness and reach of action research practices of reflexivity and transformation of power relations. In this way, more conventionally trained scientists 
might be encouraged to transform the role citizen scientists from data collectors into builders of collective community knowledge and generators of policy change.

Environmental justice researchers already emphasize the importance of these practices in the collective and meaningful involvement of communities in both street science and laboratory science to critically interrogate their assumptions about environmental risks (Corburn, 2005).

The purpose of this article is to explore the opportunities presented in the overlap between citizen science and action research by considering a case study involving youthdriven air sampling and photovoice in a Pacific Northwest community burdened by residential woodsmoke pollution. In the following sections we present a theoretical framework for analyzing such opportunities. We describe our research design by first identifying our ontological and epistemological assumptions and our processes for data collection and analysis and we describe our key findings and reflections. We conclude by discussing our processes and outcomes with regard to the potential sweet spot for participant engagement, action, and the integration of voices in combining citizen science with AR.

\section{A theoretical framework for analyzing the overlap between citizen science and AR}

Following the work of Gregory and Atkins (2018) who considered the overlap between operational research and CS, we have applied Levin's (1994) three questions for judging the effectiveness of combining citizen science and AR: 1) is the theory understood by the people and based on their interests, 2) are the research questions relevant for the people, and 3) are people emancipated to act in their own interests? These epistemological questions are suggested in a different form by Bradbury (2015a) who 
was concerned with integrating feminist groundings in action research and Chandler and Torbert's (2003) three “epistemological voices" of participatory research in relation to past, present and future activity. We have adapted both Levin's and Bradbury's ideas about action research into Table 1 . Bradbury proposes that action researchers reflect on the integration of these three voices across the dimensions of time not only to advance collaboration for transformational knowledge creation, but also as a way to "bring deeper reflection to what is present and absent in our work" (p.581). It is in this spirit that we discuss the research design and outcomes of our case example below.

Insert Table 1 here.

\section{Background to the Case study}

By virtue of the high ratio of lung volume to bodyweight, youth are vulnerable to exposures to fine particulate air pollution (PM2.5) from woodstoves; leading to increased risks for asthma exacerbations and respiratory infections (Po, FitzGerald, \& Carlsten, 2011). While indoor air pollution is recognized as a major global problem, population level data on actual exposures is lacking (Hulin, Simoni, Viegi, \& Annesi-Maesano, 2012). Woodsmoke from household woodstoves is a significant pollutant in the winter for Pacific Northwest metropolitan regions such as Tacoma, Washington State. Local geomorphological features create temperature inversions in the winter to trap airpollution. Industrial pollution has been reduced via regulations to the point where residential woodstoves are the most significant source $(53 \%)$ of PM 2.5 pollution in the colder months. In this region, government agencies have implemented a "Stove 
Reduction" action plan that includes media advertising, woodstove replacement, and increasing the number and enforcement of burn-bans (when air pollution reaches a threshold concentration). Despite such activities, community-awareness of the health risks and inequities associated with woodsmoke pollution remains low (Tacoma-Pierce County Clean Air Task Force, 2011).

Most research on residential woodsmoke has focused on determining risk and evaluating mitigation, such as governmental control or improved technology [for example Ward and Noonan (2008)]. There is a lack of published research examining residential woodstove risks with respect to environmental justice. In other words there is a lack of meaningful involvement of local knowledge (defined in this case study as experiential knowledge about wood burning in their neighborhoods) with respect to interrogating these risks and engagement in the fair treatment of community interests in actions to address these risks. As researchers, our interests in this topic stem from work on air pollution discourses in China (Eberhardt, 2015) and action research involving photovoice with Black youth with asthma (Evans-Agnew, 2017), and our partnership with a local "[Citizen] Science Shop" (Leydesdorff \& Ward, 2005) for conducting citizen science sample collection and analysis. We proposed and were funded to combine a citizen science and action research approach to work with 10 youth to conduct a photovoice project including collecting indoor air samples during burn-bans. Our stated aims in this case study were to 1) evaluate feasibility of adolescent engagement and empowerment in air sample collection and photovoice on woodsmoke and 2) describe youth discourses on environmental justice concerning woodsmoke air pollution.

\section{Research Design}


Our ontological assumption is that multiple realities exist for both the observer and the subject, and that these realities are dependent not only on the context of a given situation, but also on the dynamics of power within that situation. Our epistemological perspective is that power influences local knowledge on environmental justice and woodsmoke pollution, and that a critical analysis of the discourses of a marginalized group vulnerable to this environmental risk, in this case youth, will illuminate challenges and opportunities for collective learning, and advancing woodsmoke policy. Discourses are the patterned and linked systems of text, talk, and action located within social structures (Allen \& Hardin, 2001). In this case study the social structures of interest are those that embody woodstove use and control in a Pacific Northwest community.

Our environmental justice research design was informed by an ecofeminist framework in order to foreground the youths' local knowledge, the importance of youth collection of empirical data on the natural (air quality) environment, the potential for unjust health risks (asthma and respiratory infections) inflicted on them, and action for policy change (Chircop, 2008). The seventh principle of environmental justice adopted by the First National People of Color Environmental Leadership Summit (1991, p. 1) states the right of people to "participate as equal partners at every level" in the design, execution, and dissemination of pollution studies (including community member sampling activities) with the goal of creating change and improving health in their communities. Ecofeminist researchers are driven "by an ethic of care towards the emancipation of women and nature" (Stephens, 2015, p. 564). Ecofeminism privileges the local knowledge of both women and their children against the logic of domination and the hierarchical ordering of humans over the environment (Warren, 1990).

\section{Methods}


In this study we applied photovoice to engage youth in the documentation and dissemination of their experiences of woodsmoke air pollution through photography and air sampling and to comment on the social, political, and environmental forces influencing those experiences. Photovoice is grounded in empowerment education and places the marginalized voice at the center of collecting, interpreting and representing new knowledge (Brinton Lykes \& Scheib, 2015; Wang \& Burris, 1997).

The University of Washington Internal Review Board approved this research study for the winter of 2015-2016. We recruited a project steering committee that included community stakeholders (youth educators), policymakers (an environmentally oriented city councilperson), and health educators (school nurses) to assist with study design, recruitment, and dissemination of findings. Adolescents living in the Stove Reduction Zone in the county were recruited via flyers in schools, community centers, and through word of mouth. In the consent form for the study we stated that our purpose was to, "test a new way for teens to measure woodsmoke pollution and understand how to help teens to talk about clean air with others including community leaders". After an initial dialogic/demographic interview [to elicit participant connections between their identities and the purpose of the project, Boutain (2014)], youth participants attended three meetings and one community event during the study period. The youth received a digital camera (\$80) and a $\$ 25$ gift card for attending each meeting/event (\$100 total).

Meetings were held after-hours in a board meeting room at the county health department. We kept reflexive field-notes for each meeting. In the first meeting, they completed an empowerment pre-survey and received a 30-minute training. This training included descriptions of: 1) the impacts (human and ecological) of woodsmoke; 2) the 
lack of data on safe levels of woodsmoke; 3) local environmental justice and regional woodstove policy; and 4) the use of levoglucosan, a pyrolysis produce of cellulose, as a marker for woodsmoke. Following the photovoice method, youth were trained in basic camera techniques and ethics concerning how to take photographs of others. They were prompted to take photographs in their neighborhoods that would show "what your environment is like," and, "why your neighborhood might be more polluted than others."

In the second and third meetings we used a projector and laptop to show and discuss participant photos using the SHOWeD questioning method (Shafer, 1979; Wang \& Burris, 1997): "What do you See happening here"; "What is really Happening"; "How

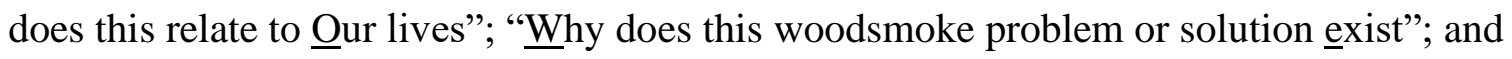
"What can we Do about it?" In the second meeting the laboratory manager from the science shop trained participants to use a high flow $(10 \mathrm{~L} / \mathrm{min})$ portable air pumps to collect up to three 24-hour indoor-air samples during burn-bans, when the concentrations of woodsmoke particulate matter would be the greatest. We used text messages to coordinate participants to simultaneously start their samplers at each data collection period. Participants took field notes on the placement of their filters and other conditions. They placed their completed samples in their home freezer until study staff transferred them to the lab.

Over the next six weeks we coordinated up to three simultaneous sampling events during burn-bans when the concentrations of woodsmoke particulate matter would be the greatest (Tacoma-Pierce County Clean Air Task Force, 2011). We invited parents and participants to attend an evening tour of the laboratory in January where the samples were being analyzed. In the third session (February) participants discussed and analyzed their 
sampling results using the SHOWeD method; and then individually selected two photographs to create a title and caption (phototext) for display at a community event (March). This event was held with parents, community members, the press, and air pollution policy makers. During the community event participants stood by their framed photographs and phototexts and air sampling data from their homes and discussed their findings with attendees. Youth engagement concluded at this event with a postparticipation empowerment and evaluation survey.

Samples were analyzed by the laboratory manager at the science shop for Levoglucosan using Mass Spectrometry based on established methods (Ward \& Noonan, 2008). He worked with youth in session three to determine the best way to present the data. They selected histograms indicating levoglucosan levels for each home and the printing of one large poster depicting the geographic locations and samples from each home.

After the final community event we (the authors of this article) critically analyzed the youth selected phototexts and photos. We employed an ecofeminist lens (i.e. local knowledge of woodsmoke, responses to empirical data, awareness of structural oppressions, and calls for action) to explore the power relations between youth and other dominant (i.e. governmental/societal) discourses on woodsmoke (Chircop, 2008; Fairclough, 2009). We completed the analysis over three phases: 1) summarizing governmental/societal discourses on woodsmoke and environmental justice including our own published work in this area (Evans-Agnew, Compson, \& Lower, 2015) and from the session-one lesson given to the youth; 2) identifying discursive topics within each phototext (phototexts may have multiple arguments including persons, actions, and 
events), and 3) identifying whether youth were introducing a new discourse or promoting an existing discourse. We sought methodological rigor through multiple readings of the phototexts and reflective journaling.

\section{Sample}

The ten participants described themselves as either boys or young men $(n=7)$ and girls or young women $(n=3)$ from both middle $(n=6)$ and high schools $(n=4)$ living in a variety of rural and urban locations across the Stove Reduction Zone with an average length of residence of 5.3 years. They self-described their various (and mixed) racial and ethnic identities as White (n=6), Black ( $n=3)$, and Mexican (2), Asian, Indian, Sicilian, New Zealand, European, Norwegian, and various northern and southern states in the USA. Only one participant had a working wood stove but the nine others were aware of wood burning in their neighborhoods. Parent/guardian occupations included the military $(n=2)$, management positions $(n=3)$, skilled labor $(n=3)$, service industry $(n=3)$, and educators or health professions $(n=2)$. Most $(n=8)$ had at least one person living in the home with asthma, lung disease, or diabetes.

Youth identified various reasons for participating including helping the world or community $(n=4)$, fighting pollution $(n=2)$, learning about the environment $(n=3)$, and science. Youth were also asked to identify what part of their identity was most important for "keeping the air clean" as part of the dialogic/demographic interview (Boutain, 2014). They identified their neighborhood, their families $(n=2)$ and their family health issues $(n=4)$, their desire to keep the environment clean $(n=2)$, their education, and the fact that one of them owned a working woodstove.

\section{Results}




\section{Feasibility of youth empowerment and youth sampling}

Youth empowerment increased and these results have been reported elsewhere (Brickle \& Evans-Agnew, 2017). Youth collected 24 air samples (mean=2.4 samples per youth) in their homes over three sampling periods: two during one burn-ban over the Thanksgiving holiday $(n=7, n=7)$ and another burn-ban $(n=10)$ two weeks later. The laboratory manager identified levels of Levoglucosan every sample, ranging from 10.8$3146.0 \mathrm{ng} / \mathrm{m}^{3}$ with an average concentration of $698.7 \mathrm{ng} / \mathrm{m}^{3}$. The reasons given for missed sampling events $(n=6)$ included equipment failure, mis-communication (the parents thought that the sampler should have been placed outdoors), and parent complaints that the pumps were too noisy.

Participants returned 41 photographs for the second group meeting and discussed 18. For the third and final meeting, participants took an additional 46 photographs. Out of the total of 87 photographs, each youth selected two of their photos for a total of twenty photos and phototexts to display at the community meeting. Seven youth attended all three meetings and three youth each missed one meeting because of sickness. The research team made separate visits to each of the youth who missed a session to complete their photo selection and creation of phototexts.

\section{Critical discourse analysis of photos and phototexts}

We analyzed phototexts within an ecofeminist framework (Chircop, 2008) and identified 19 discourses on local knowledge, empirical evidence, structural oppressions, and discourses on taking action and we identified 86 strands of text within these discourses (Table 2). We compared these youth discourses to dominant (societal) discourses from 1) the education in session one, 2) government [Clean Air Agency and 
Environmental Protection Agency] c, 3) local [adult] environmental justice community (Evans-Agnew et al., 2015), and 4) discourses on the scientific method. Four discourses unique to the youth participants included two topics within local knowledge (woodsmoke is invisible, woodsmoke affects neighborhoods differently), one topic within the discourses of empirical data (surprise at finding woodsmoke in their homes), and one topic within the taking action discourse (open more homeless shelters to decrease outdoor burning)

Insert Table 2 here.

The four photos and phototexts below illustrate the complexities of the youth discourses within an ecofeminist lens. Youth exposure to empirical data and the scientific process for collecting, analyzing, and discussing their air samples elicited photos and phototexts that appeared to grapple with the texts, talk, and actions involved with discourses on the scientific process $(n=9)$. For example one photo (Figure 1, Where the Process Begins) depicts a rack of test tubes and materials needed to analyze the sample. The youth states in the phototext that his photo shows the analytical "process from start to finish", and while certainly clearly described, it is still a fragment of the analytical steps the youth actually experienced.

Insert Figure 1 here "Where the process begins".

Other youth phototexts grappled with discussing the scientific methods and their 
surprise at finding that woodsmoke was found in every home despite the almost complete absence of woodstoves in these homes $(n=4)$. In the photo and phototext entitled "Smoking Clouds" (Figure 2.) for example the youth states, "I was surprised to find there was woodsmoke in the sample I took. It is pretty unbelievable woodsmoke is in our houses". In this phototext he also describes his photo of the smokestacks of the pulp and paper mill that is locally notorious for producing a detectable odor for residents in the area. In this way he promotes an environmental justice discourse concerning environmental degradation, "the more trees they cut down the more smoke there will be in the air."

Insert Figure 2 here "Smoking Clouds"

The environmental justice frame behind the youth education session elicited photos and phototexts that advanced existing ecocentric discourses in creative ways. For example in Figure 3, the same youth that had described the scientific process (see Figure 1) invokes the voice of a tree in discussing how the trees are, "breathing in little bits of their family [from the woodsmoke] and are having a hard time remaining Healthy (sic)".

Insert Figure 3 here "Stop burning my cousins: you are killing me".

Youth participants used their photos and phototexts to advance a variety of arguments for taking action $(n=18)$. For example one youth employed the ecofeminist frame to uplift the different voices or "Point of View's" that people have on woodsmoke 
pollution (Figure 4). Rather than advancing one argument for woodsmoke, she acknowledged the complexity of perspectives and asserted a call to action on woodsmoke, “...it needs to be minimized, it still affects our air, or better yet it needs to stop." This was the same youth that created a photo and phototext of a homeless encampment with an outdoor fire that she had driven past with her mother, advancing existing environmental justice discourses on poverty and wood burning and introducing a unique action discourse on decreasing outdoor burning through housing the homeless.

Insert Figure 4 here "Points of view's".

\section{Policy change outcomes}

Two policies were affected by this project. Over 40 persons attended the photovoice event including parents, youth, policy makers, asthma and environmental health advocates, and the reporter from the local newspaper. The two policymakers in the audience were the environmental health manager of the county health department and the head of the regional Clean Air Agency. Both individuals were responsible for advocating for and managing budgets related to maintaining air quality in the woodstove reduction zone. In addition to receiving favorable press from the event, it was soon after this meeting that the asthma program at the county health department was merged with the air quality program. One official from this program emailed us with news that state funding had been appropriated for woodstove changeout, commenting that our project "got great attention at the time when legislators were deciding whether or not to keep the line item in the budget or not. What a win!" 


\section{Reflexive and observational data}

Our original proposal was greeted favorably by two of our three reviewers, but the third requested greater consideration for, "the issues and opportunities of learning within citizen science programs, particularly for young people. Citizen science's impacts on lay people have been mixed at best." In our revision we emphasized our partnership with a science shop with experience in citizen science and our training component of the first session.

As White male researchers we were conscious of our privilege and the difficulties in assuring inclusion of voice and balancing of power amongst youth participants who themselves varied by race, class, and gender. We had intentionally involved three student research assistants (claiming identities as mothers, single, female, Black, Black/Asian, and White) to assist us with data collection and observation. This was an important inclusion especially for the teenage girls in the study. For example one observed that we were favoring the boys in terms of seating them at the table but splitting up two girls who were friends, stating, “J. \& H. were visibly disappointed that they couldn't sit next to each other."

Our notes reflect several of the youth had difficulties in fully participating that were beyond their control: a father who was struggling with an opiate addiction ("N. didn't show up. I was concerned so I texted his mom at 4:19 pm and she responded at 5:12 pm, I took a breath before reading the text. Family emergency, took his dad to urgent care"); a mental disability that interfered with their ability to process information and speak ("P. was worried his hands would be too big for the gloves. I realize [now] that 
the steps might be too confusing for him...”); a working class mother who was between jobs (“A. couldn't make the community event (new job training for her mother) so I drove over to her house, I wish we had had a way for her to make it to the event"); and a low-income family living in their parent's small cabin ('Z Z. was sick, [he has asthma...maybe from the woodsmoke?] So I drove over to his cabin to help him finish the phototexts").

In the community event we observed that people were: 1) moved by the photographs of the homeless encampment; 2) "shocked" that woodsmoke was found in every home; and 3) frustrated about the lack of community awareness of woodsmoke health risks, burn-bans, and woodstove changeout. We observed that community members agreed (on prompting from the one of us who was facilitating) that it was both "an environmental justice issue" and a "challenge for the youth present to go into the sciences to find renewable energy that is affordable".

As researchers we were more conscious of the power-relations in the room than the community members because of our prior experiences working with the agency and press stakeholders. In one interaction we observed that the laboratory manager who had trained the youth in sample collection and performed the analysis directly challenged the Clean Air Agency director about what to do after all the funds for woodstove changeout had been exhausted. One of us [the facilitator] noted, "I remember being conscious of thinking I need to protect K. [the director], not have it be awkward for him, and then on the other hand realizing this is precisely what is supposed to happen in Photovoice..."

At one point in the evening the press reporter approached us about publishing only the photo and not the phototext of one participant (Figure 4) in the local newspaper. 
She explained that she did not have any power over the choice of caption for the photograph, that another department handled this choice. We conferred with the youth and she refused to let them publish her photo without her phototext. The paper instead published an article on the front page of the local section using the reporters' photo that was taken at the event of a youth holding his photo. The caption did not use his phototext.

\section{Discussion.}

In this case study we employed an environmental justice framework in the engagement of ten youth in the collection, analysis, and dissemination of photos and home air-sample data. We critically examined discursive practices of the youth participants with regard to engaging in scientific discovery and action. Through citizen science laboratory analysis of air samples, participants discovered that they were exposed regardless of wood stove ownership and they grappled with scientific discourses to explain to others the discordance between this finding and their assumptions about their environmental risks. Through photovoice, youth negotiated the subjective and intersubjective terrains of local knowledge with our research team, discussed structural inequities concerning objective woodsmoke pollution data with the public, and initiated action for increased woodsmoke prevention funding with policymakers.

In addressing our two aims, we demonstrated that photovoice is a feasible method in combining principles from both citizen science and action research movements through youth data collection and reflection and action on woodsmoke environmental justice. Through the implementation of this case study, we generated youth discourses on woodsmoke air pollution and action. Youth grappled with scientific discourses to critique their initial assumptions about their exposure to woodsmoke in their homes. Youth 
adopted discourses from our educational lessons and other governmental and environmental justice influences. The findings in this case study provide insight into the fruitfulness of combining citizen science and action research for eliciting subjective, intersubjective, and objective epistemological voices (Table 3) by addressing the questions posed by Levin (1994). The following section discusses these opportunities.

Insert Table 3 here

\section{Was the theory understood by the youth and based on their interests?}

We noted that the citizen science aspects of the study were foregrounded by the reviewers of our grant application (Table 3). While our consent form described (in lay language) our interests in citizen science and action research, we made the choice to employ environmental justice and ecofeminism without consulting the youth. We shared both the citizen science and action research aspects of the theory (and included past government and environmental justice work on woodsmoke) with the youth in session one, this finding suggests that the theoretical design may have been less understood by participants than we had desired it to be. Our dialogic/demographic interview procedure (Boutain, 2014) did however elicit first person motivations for participating and allowed the youth to locate their identity within the goals of the research project.

\section{Were the research questions relevant for the youth?}

Youth were empowered intersubjectively and subjectively and in their group discussions and subsequent individual creation of their phototexts to grapple with the scientific process by both (partially) describing it for others (e.g. in Figure 1) and 
adapting to the discordance between their assumptions of risk (street science) and the empirical data (lab science) they collected. For example in Figure 3 ("Smoking Clouds"), the youth promoted a discourse that linked corporate logging to woodsmoke pollution that he saw outside his home (street science) and his own experience of harm ("living here, I can't run as far") and employed a scientific discourse to discuss how he collected the sample for the lab.

Youth used their photos and phototexts to promote existing anthrocentric and ecocentric discourses on environmental justice. For example, in Figure 2 the same youth that promoted a strong scientific discourse in Figure 1 this time embodied the voice of a tree that is being poisoned by woodsmoke. The multiple realities encouraged in ARbased designs are celebrated by the youth who produced the photo "Point of View's" (Figure 4) arguing that perspectives on woodsmoke can indeed shift and are not static. Permitting youth to shift between anthrocentric to ecocentric perspectives is a distinct advantage within this research design, employing what Stephens' (2015) describes as the drive within cultural ecofeminism to not only center nature but also to reject positivism in favor of "viewing things as interrelated and networked" (Stephens, 2015, p. 566). Combining citizen science and action research within a photovoice project thus undermined the dualism between objective ("superior") air samples and photos and the subjective ("inferior") phototexts through the co-creation and design of the disseminated data for the community meeting. In other words youth were transformed from data collectors to builders of community knowledge and generators of policy change through the integration of their subjective, intersubjective, and objective voices on woodsmoke pollution. Further, the opportunity for researcher reflexivity offered in 
this combined design provided indications as to our relative success in achieving this integration.

In Bradbury’s (2015a) conceptualization (Table 1) the third person (present time) voice promotes the institutionalization of knowledge. Through combining citizen science air sample and photo collection and photovoice the youth were able to share objective data and their analyses at the community meeting. Our notes reflect that the attendees applied a value to this "scientific" epistemology and demanding action. This confirms to us the importance of a dissemination event for achieving relevance for youth of the objective epistemological voice within an action research and citizen science research design.

\section{Were youth emancipated to act in their own interests?}

The youth discourses described in Table 2 indicate that the youth within our action research design were thinking critically and working towards emancipation. The community event provided for some intersubjective collaboration on discussing the need for better communication and science but these plans were not advanced beyond this meeting (Table 3). We did not encourage collaboration for future plans and we ended youth involvement at the conclusion of the community event. Intersubjective reflexivity and collaboration for future planning has been a noted challenge for action research designs that employ photovoice (Brinton Lykes \& Scheib, 2015). While critical analysis of data has been suggested as central to action research (Kemmis, McTaggart, \& Nixon, 2015), our own experience has been that it is very challenging to teach critical discourse analysis to participants. In this case study our approach as researchers to distance ourselves from participants in order to perform a critical analysis of the texts is more in- 
line with citizen science approaches.

Our policy outcomes indicate that the Clean Air Agency and health department stakeholders were influenced by objective data from our event to advance improvements (and funding streams) within their own systems. Yet the approaches to the protections and ownership of objective data in our design might be interpreted differently between citizen science and action research movements. For example we noted our observations concerning the argument with the newspaper reporter and the youth's decision to not let them publish her photo without her phototext (Figure 4). It is not clear that this would have happened inside a CS-only design as the phototext might be undervalued (as it was by the reporter) as subjective data. As we and other observers have noted, photovoice designs often compromise participant voice in the interests of dissemination (Brinton Lykes \& Scheib, 2015; Evans-Agnew \& Rosemberg, 2016).

\section{Conclusion}

This case study demonstrates that photovoice, when applied through critical methodologies involving both citizen science and core action research principles of reflexivity and action can broaden the epistemological reach of participatory research. Combining citizen science and action research provides opportunities for engagement and transformation of traditionally positivistic (first order) scientific disciplines into second order transformational research where the focus is on recognizing science as intervention (Fazey et al., 2018). The citizen science movement's interests in scientific activities that promote actions and engage participants in all stages of the research can only be in concert with second order transformational research if citizen science researchers acknowledge the need for action research reflexivity as we did in this case study. 
The combination of citizen science and action research in this case study suggests new ways to engage marginalized populations in discovery and action. Photovoice provides an accessible way for participants from multiple backgrounds to build capacity for ongoing collective learning and action against emerging health and environmental threats. In our case study we noted that youth (and their parents) were interested in using science to make change. Others have noted the importance of including feminist theory in photovoice for engaging new voices in contesting dominant discourses on environmental justice and social change (Brinton Lykes \& Scheib, 2015). The combination of citizen science and action research provided new entry points for engaging marginalized groups of youth in future involvement in both scientific research and environmental advocacy.

In this research study we explored the opportunities presented in the overlap between citizen science and action research by describing and discussing a small case study of 10 youth who combined photovoice with air sample collection. We found that citizen science can be informed by the reflexivity and change in power relations that is encouraged in action research. Combining these movements in a well-designed and facilitated social learning environment has the potential to more fully integrate knowledge from the experiences of diverse stakeholders with empirical data. Our case study suggests that this combination creates new avenues for collaboration between more conventionally trained scientists and activist research movements. We described how the youth participants in our case study were transformed from woodsmoke air pollution data collectors into generators of policy change through their phototexts concerning woodsmoke, empirical data, and their arguments for action. Through the mutual influences of citizen science and action research, stakeholders may be able to collectively 
understand complex challenges more deeply, develop a narrative, and take action to advance a collective vision. 


\section{References}

Allen, D., \& Hardin, P. K. (2001). Discourse analysis and the epidemiology of meaning. Nursing Philosophy, 2(2), 163-176. doi: 10.1046/j.1466-769X.2001.00049.x

Averett, N. (2017). New Blood: The Promise of Environmental Health Citizen Science Projects. Environ Health Perspect, 125(11), 112001. doi:10.1289/ehp2484

Bonney, R., Cooper, C., \& Ballard, H. (2016). The Theory and Practice of Citizen Science: Launching a New Journal. Citizen Science: Theory and Practice, 1(1), 1. doi:10.5334/cstp. 65

Boutain, D. M. (2014). The identity, research, and health dialogic interview: Its significance for social justice-oriented research. In P. N. Kagan \& P. L. Chinn (Eds.), Philosophies and practices of emancipatory nursing: Social justice as praxis. (pp. 124-135). New York: Routledge.

Bradbury, H. (2015a). The integrating (Feminine) reach of action research: a nonet for epistemological voice. In H. Bradbury (Ed.), The SAGE handbook of action research (Third ed., pp. 573-582). Los Angeles, CA: SAGE.

Bradbury, H. (2015b). Introduction: How to situate and define action research. In H. Bradbury (Ed.), The SAGE handbook of action research (Third edition. ed., pp. 112). Los Angeles, CA: SAGE.

Brickle, M. B., \& Evans-Agnew, R. (2017). Photovoice and Youth Empowerment in Environmental Justice Research: A Pilot Study Examining Woodsmoke Pollution in a Pacific Northwest Community. J Community Health Nurs, 34(2), 89-101. doi:10.1080/07370016.2017.1304148

Brinton Lykes, M., \& Scheib, H. (2015). The artistry of emancipatory practice: 
Photovoice, creative techniques, and feminist anti-racist participatory action research. In H. Bradbury (Ed.), The SAGE handbook of action research (Third edition. ed., pp. 131-142). Los Angeles, CA: SAGE.

Chandler, D., \& Torbert, B. (2003). Transforming Inquiry and Action: Interweaving 27 Flavors of Action Research. Action Research, 1(2), 133-152. doi: $10.1177 / 14767503030012002$

Chircop, A. (2008). An ecofeminist conceptual framework to explore gendered environmental health inequities in urban settings and to inform healthy public policy. Nursing Inquiry, 15(2), 135-147. doi: 10.1111/j.1440-1800.2008.00400.x.

Corburn, J. (2005). Street science : community knowledge and environmental health justice. Cambridge, MA: Cambridge, MA : MIT Press.

Eberhardt, C. (2015). Discourse on climate change in China: A public sphere without the public. China Information, 29(1), 33-59. doi:10.1177/0920203X15571261

European Citizen Science Association. (2015). The Ten Principals of Citizen Science. Retrieved from http://ecsa.citizen-science.net/documents

Evans-Agnew, R. A. (2017). Asthma Disparity Photovoice: The Discourses of Black Adolescent and Public Health Policymakers. Health promotion practice, 9. doi:10.1177/1524839917691039

Evans-Agnew, R. A., Compson, J., \& Lower, C. S. (2015). Bridging the interdisciplinary divide: co-advancing the pedagogy of environmental justice through a digital commons initiative. Interdisciplinary Environmental Review, 16(2/3/4). doi:10.1504/IER.2015.071017

Evans-Agnew, R. A., \& Rosemberg, M. A. (2016). Questioning Photovoice Research: 
Whose Voice? Qual Health Res, 26(8), 1019-1030.

doi:10.1177/1049732315624223

Fairclough, N. (2009). A dialectical-relational approach to critical discourse analysis in social research. In R. Wodak \& M. Meyer (Eds.), Methods of critical discourse analysis (pp. 162-185). London; Thousand Oaks [Calif.]: SAGE.

Fazey, I., Schäpke, N., Caniglia, G., Patterson, J., Hultman, J., van Mierlo, B., . . . Wyborn, C. (2018). Ten essentials for action-oriented and second order energy transitions, transformations and climate change research. Energy Research \& Social Science, 40, 54-70. doi:10.1016/j.erss.2017.11.026

First National People of Color Environmental Leadership Summit. (1991). 17 principles of Environmental Justice. Paper presented at the First National People of Color Environmental Leadership Summit Washington, DC. http://www.columbia.edu/cu/EJ/Reports_Linked_Pages/EJ_principles.pdf

Gregory, A. J., \& Atkins, J. P. (2018). Community Operational Research and Citizen Science: Two icons in need of each other? European Journal of Operational Research, 268(3), 1111-1124. doi:https://doi.org/10.1016/j.ejor.2017.07.037

Hulin, M., Simoni, M., Viegi, G., \& Annesi-Maesano, I. (2012). Respiratory health and indoor air pollutants based on quantitative exposure assessments. European Respiratory Journal, 40(4), 1033-1045. doi:10.1183/09031936.00159011

Irwin, A. (1995). Citizen science : a study of people, expertise, and sustainable development. London: Routledge.

Kemmis, S., McTaggart, R., \& Nixon, R. (2015). Critical theory and critical participatory action research. In H. Bradbury (Ed.), The SAGE handbook of action research (Third edition. ed., pp. 454-464). Los Angeles, CA: SAGE. 
Levin, M. (1994). Action research and critical systems thinking: Two icons carved out of the same log? Systems Practice, 7(1), 25-41. doi:10.1007/BF02169163

Leydesdorff, L., \& Ward, J. (2005). Science shops: a kaleidoscope of science-society collaborations in Europe. Public Understanding of Science, 14(4), 353-372. doi: $10.1177 / 0963662505056612$

Po, J. Y., FitzGerald, J. M., \& Carlsten, C. (2011). Respiratory disease associated with solid biomass fuel exposure in rural women and children: systematic review and meta-analysis. Thorax, 66(3), 232-239. doi:10.1136/thx.2010.147884

Shafer, R. (1979). Beyond the Dispensary (On Giving Balance to Primary Health Care) (pp. 90). Retrieved from http://www.amoshealth.org/wpcontent/uploads/2012/07/Beyond-The-Dispensary-by-Roy-Shaffer-Book.pdf.

Stephens, A. (2015). Ecofeminism and systems thinking: Shared ethics of care for action research. In H. Bradbury (Ed.), The SAGE handbook of action research (Third edition. ed., pp. 564-572). Los Angeles, CA: SAGE.

Tacoma-Pierce County Clean Air Task Force. (2011). Report and recommendations to the Pierce County Clean Air Agency. Retrieved from Tacoma, WA: http://www.cleanairpiercecounty.org/taskforce/index.aspx

Wang, C. C., \& Burris, M. A. (1997). Photovoice: Concept, methodology, and use for participatory needs assessment. Health Education \& Behavior, 24(3), 369-387. doi:10.1177/109019819702400309

Ward, T., \& Noonan, C. (2008). Results of a residential indoor PM 2.5 sampling program before and after a woodstove changeout. Indoor Air, 18(5), 408-415. doi:10.1111/j.1600-0668.2008.00541.x

Warren, K. (1990). The Power and the Promise of Ecological Feminism. Environmental 
Ethics, 12(2), 125-146. doi: enviroethics199012221 